\title{
INTEGRATION OF GIS AND BIM FOR INDOOR GEOVISUAL ANALYTICS
}

\author{
B. Wu, S. Zhang \\ Department of Land Surveying \& Geo-Informatics, The Hong Kong Polytechnic University, Hung Hom, Kowloon, Hong Kong - \\ bo.wu@polyu.edu.hk
}

Commission II, WG II/6

\begin{abstract}
:
This paper presents an endeavour of integration of GIS (Geographical Information System) and BIM (Building Information Modelling) for indoor geovisual analytics. The merits of two types of technologies, GIS and BIM are firstly analysed in the context of indoor environment. GIS has well-developed capabilities of spatial analysis such as network analysis, while BIM has the advantages for indoor 3D modelling and dynamic simulation. This paper firstly investigates the important aspects for integrating GIS and BIM. Different data standards and formats such as the IFC (Industry Foundation Classes) and GML (Geography Markup Language) are discussed. Their merits and limitations in data transformation between GIS and BIM are analysed in terms of semantic and geometric information. An optimized approach for data exchange between GIS and BIM datasets is then proposed. After that, a strategy of using BIM for 3D indoor modelling, GIS for spatial analysis, and BIM again for visualization and dynamic simulation of the analysis results is presented. Based on the developments, this paper selects a typical problem, optimized indoor emergency evacuation, to demonstrate the integration of GIS and BIM for indoor geovisual analytics. The block Z of the Hong Kong Polytechnic University is selected as a test site. Detailed indoor and outdoor 3D models of the block Z are created using a BIM software Revit. The 3D models are transferred to a GIS software ArcGIS to carry out spatial analysis. Optimized evacuation plans considering dynamic constraints are generated based on network analysis in ArcGIS assuming there is a fire accident inside the building. The analysis results are then transferred back to BIM software for visualization and dynamic simulation. The developed methods and results are of significance to facilitate future development of GIS and BIM integrated solutions in various applications.
\end{abstract}

\section{INTRODUCTION}

The main functions for Geospatial Information System (GIS) are to capture, store, manipulate, analyse, manage, and present all types of spatial or geographical data. Its capability in handling spatial data has facilitated it use in various applications. Building Information Modelling (BIM) is an intelligent modelbased process that provides insight for creating and managing building and infrastructure projects faster and more economical (Eastman et al., 2011). It offers a novel approach to design, construction, and facility management in which a digital representation of the building process is used to facilitate the exchange and interoperability of information in digital format. BIM is beginning to change the way buildings look, the way they function, and the ways in which they are designed and built

Both GIS and BIM are creating digital representation of the real world, while in different ways and different dimensionalities. GIS describes macro-level of the objects on earth e.g. cities, landforms, and outdoor environment which are related with exact geographic coordinates. While BIM pays more attention on defined objects like buildings and on detailed indoor design which are in micro level of entities of the world. GIS has the advantages of the spatial analysis such as overlay analysis and network analysis, while BIM has the advantages of indoor 3D modelling and dynamic simulation. This paper presents an endeavour of integration of GIS and for indoor geovisual analytics.

\section{FUNDAMENTALS OF GIS AND BIM INTEGRATION}

BIM affords primary data for built environment used in spatial analysis and GIS packed spatial text for BIM models (de Laat and van Berlo, 2011). The essential differences of these two approaches are their defining languages. For GIS, it is the Geography Mark-up Language (GML) standard. While for BIM, it is the Industry Foundation Classes (IFC) standard.

\subsection{GIS and City GML Standard}

GML is the XML grammar defined by the Open Geospatial Consortium (OGC) to express geographical features. In most cases, based on XML grammars, there are two parts to this grammar, one is schema describes the document and the other is instance document contains the actual data. So that City GML data standard can represent geographical information of one building in digital 3D city models (Cheng et al., 2013). GML is also an ISO standard with number ISO 19136:2007.

\subsection{BIM and IFC Data Standard}

The IFC data model is intended to describe building and construction industry data. It is an object-based file format with a data model developed by building SMART, an International Organization (formerly the International Alliance for Interoperability, IAI) to facilitate interoperability in the architecture, engineering and construction (AEC) industry, and is a commonly used collaboration format in BIM based projects.

ISO 16739:2013 specifies a conceptual data schema and an exchange file format for BIM data (ISO, 2013). The ISO standard represents an open international standard used for sharing and exchanging BIM data, like construction, facility management, electro mechanical, among different software systems.

\subsection{IFC and GML Data Integration}

BIM model cannot be read by GIS software (e.g., ArcGIS) directly. First, BIM model should be semantically filtered to obtain IFC objects and also stored with IFC semantic information. BIM model can be processed through morphology algorithm and Boolean operation to screen out the shell of buildings and obtain correct semantic information (Donkers, 2013). Semantic mapping can be used to get CityGML models, of which most parts can have mapping relationships with the 
IFC objects. In this process, the level of details (LOD) of City GML object should be set first. Different LOD of City GML model have different corresponding geometric information. For example, room in LOD1 is just a box without a door and window. While in LOD4, the interior wall and outer wall should be separated, the same as roof and floor.

After LOD of City GML is set, the next step is to transform geometric information between GML and IFC models. For one IFC model, its geometric information and related attribute data can be outputted through geometric information filtering. The semantic mapping methods include one-to-one mapping and one-to-many mapping and indirect mapping (Tang et al., 2014).

The final step is to redefine the geometric and semantic information in CityGML mode, so that to fulfil the whole process of converting one IFC model into CityGML model. Nowadays there are a number of third-party software tools can do this through interfaces and extensions in an automatic way. Figure 1 shows the flow of data transformation between BIM and GIS.

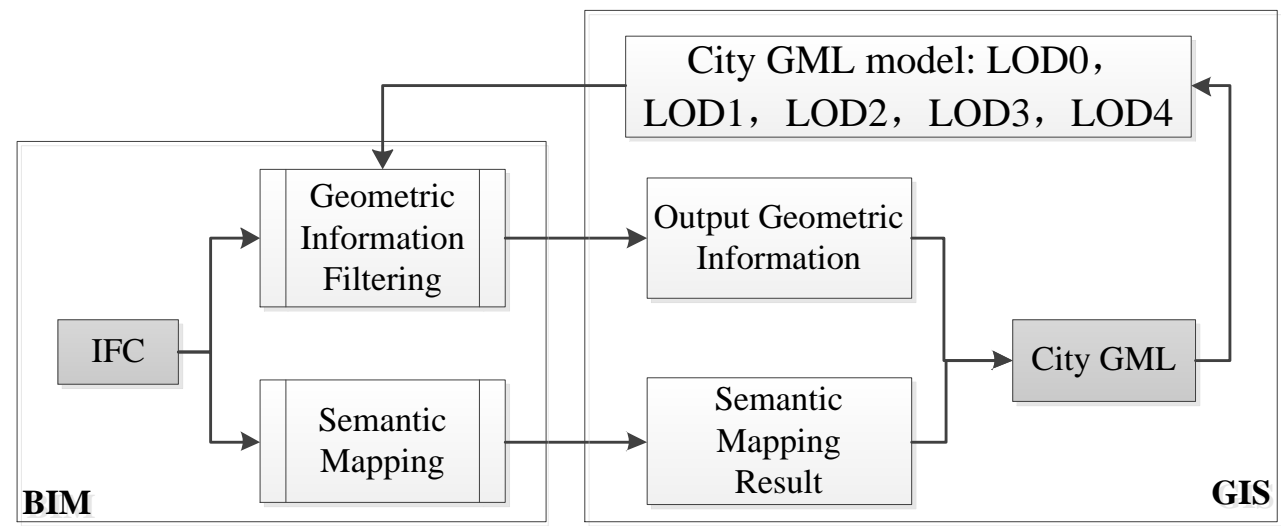

Figure 1. Data transformation between BIM and GIS

\section{INTEGRATION OF GIS AND BIM FOR INDOOR GEOVISUAL ANALYTICS}

This research selects the block Z of the Hong Kong Polytechnic University as a test site to investigate and demonstrate the integration of GIS and BIM for indoor indoor emergency evacuation analysis.

\subsection{D Modelling Using Revit}

The typical BIM software by Autodesk Company, Revit, is used to build $3 \mathrm{D}$ models of the test site. The main input for 3D modelling is the floor plan of the building and the files are in CAD format. Figure 2 shows an example of the floor plan of the block $\mathrm{Z}$ in Revit. Figure 3 show the 3D modelling results using Revit.

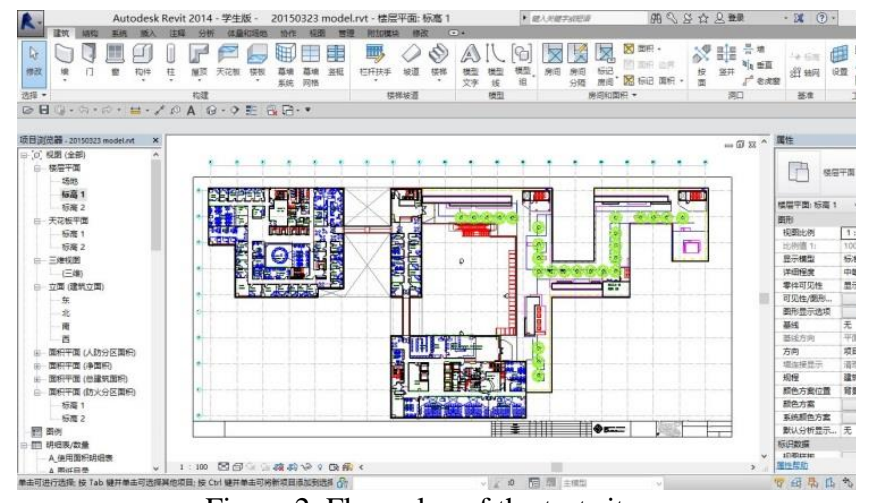

Figure 2. Floor plan of the test site

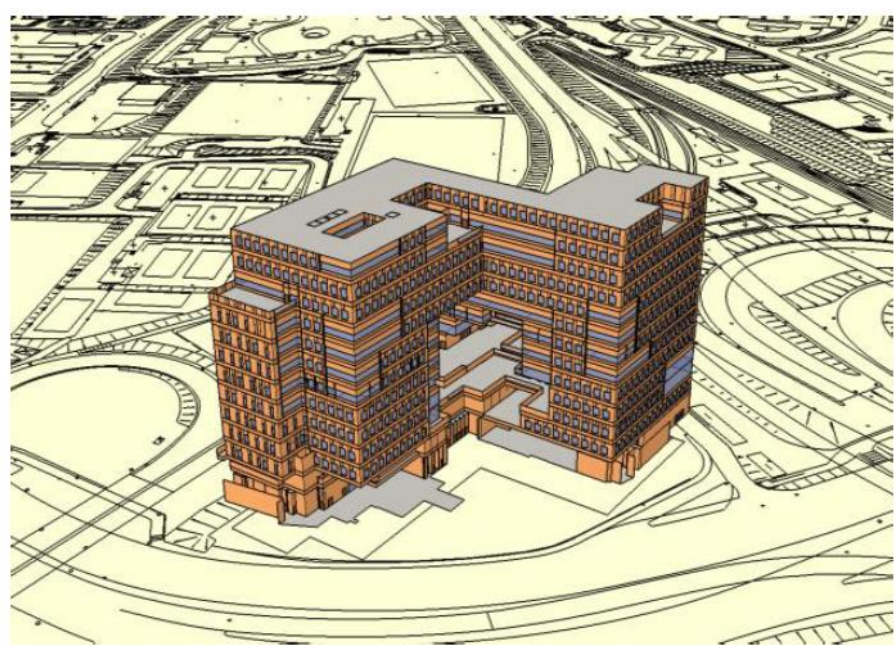

(a)

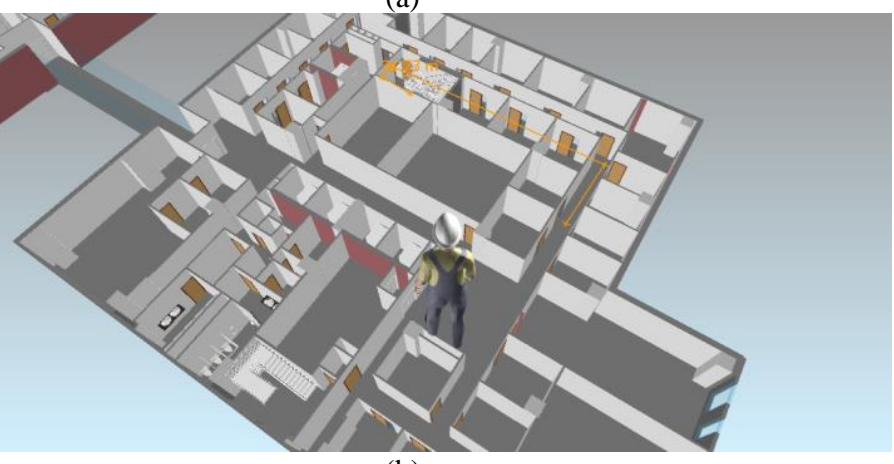

(b)

Figure 3. 3D model of the text sit. (a) Geo-referenced 3D model on a 1:1000 base map, and (b) a detailed view of the indoor models. 


\subsection{Transformation of BIM Models to GIS}

The 3D models built in Revit can be exported to IFC format (see figure below) and then they can be imported into ArcGIS. In ArcGIS, select the toolbox "Arc Toolbox" - "Data Interoperability Tools" -"Quick Import", and then in the dropdown list, chose "Industry Foundation Class STEP Files (IFC)" as the input dataset format. After the process the Revit models can be transformed into IFC files and shown in ArcScene (Figure 4).

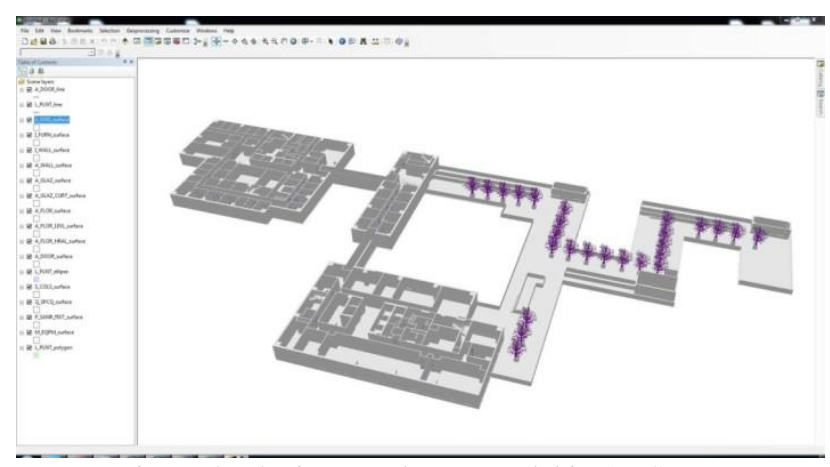

Figure 4. The imported BIM model in ArcScene

After importing the models into ArcGIS, the models are classified into eighteen types of objects representing the inner components of buildings such as walls, stairs, doors, furniture and etc.

\subsection{Building Topology in GIS}

This step separates all the rooms including offices, toilets, storerooms, etc., and examines their connections with the corridors. For most of the corridors, their centrelines are used as routes. For large spaces, the lines along the diagonal directions of the boundaries are used as routes.

After obtaining the individual rooms and routes, they are connected to form a topological network as show in Figure 5. The following emergency evacuation analysis is based on this topological network.

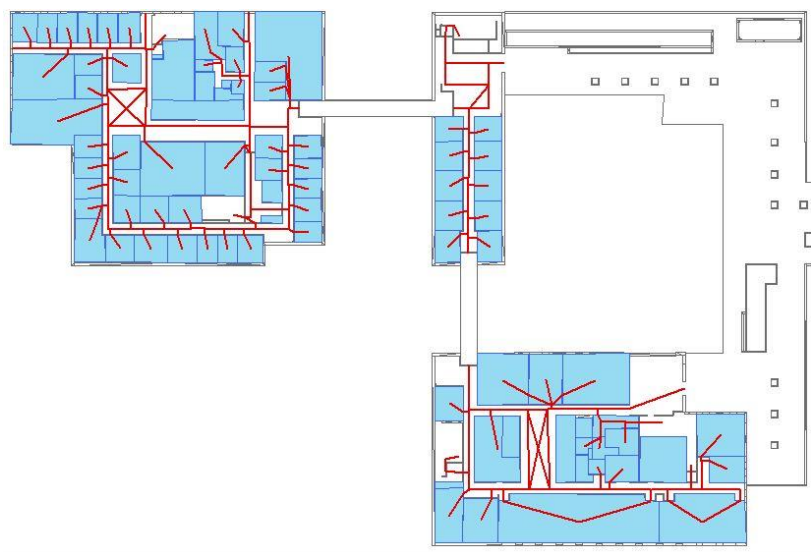

Figure 5. The generated topological network map in GIS

\subsection{Emergency Evacuation Analysis in GIS}

Assuming there is a fire point inside the building, and GISbased network analysis is carried out to help finding the possible evacuation routes based on the above topological map. Figure 6 shows an example of the optimal evacuation routes obtained based on network analysis in ArcGIS.

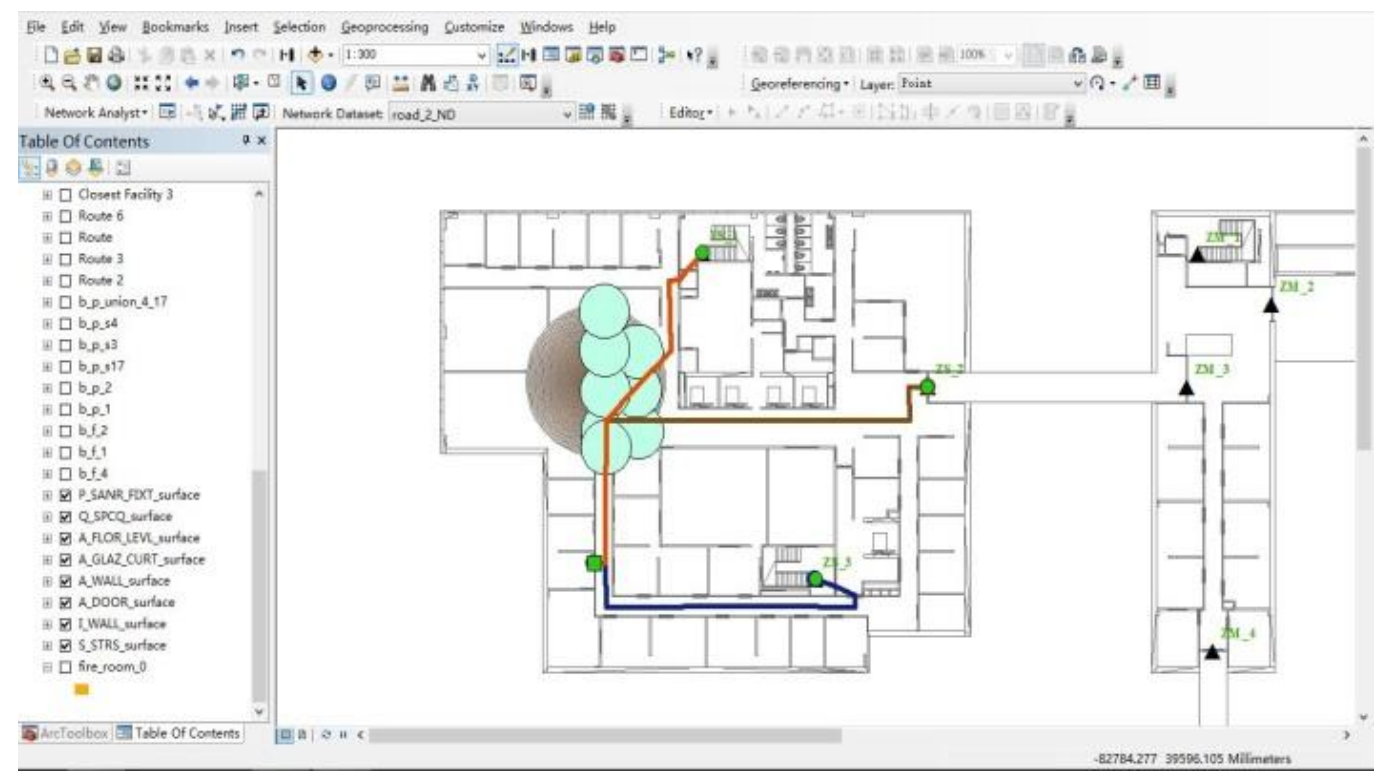

Figure 6. Example of optimal evacuation routes based on network analysis

\subsection{Visualization and Simulation of Emergency Evacuation Routes in BIM}

After obtaining the optimal evacuation routes through network analysis in ArcGIS, the results are visualized and simulated in BIM for better understanding and demonstration of the routes.
Another software, Navisworks, is employed here for better simulation of the fire animation. The Revit models are firstly imported into Navisworks, and the obtained evacuation routes are also represented in 3D in Navisworks. Figure 7 shows an example of the evacuation route illustrated in Navisworks. 


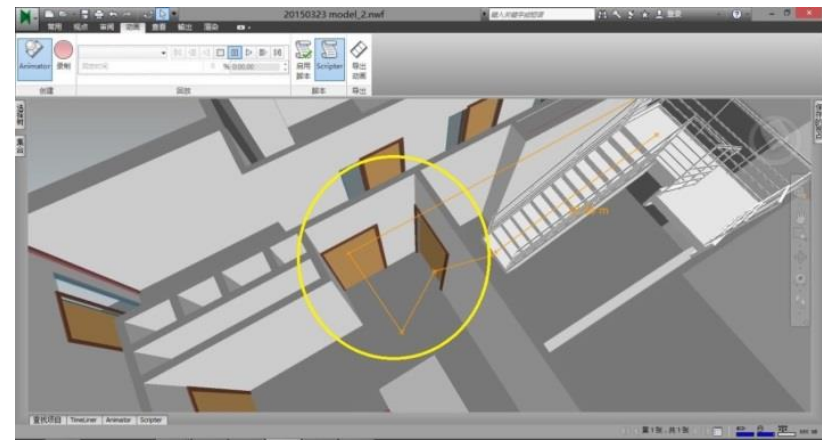

Figure 7. An example of the evacuation route in Navisworks

It should be noted that, based on the BIM software, object-based animation can be conveniently implemented for better visualization and simulation of the evacuation routes.

\section{CONCLUSIONS AND DISCUSSION}

In this paper we have presented an endeavour to integrate GIS and BIM for indoor geovisual analytics. The developments and results show that it is feasible to combine these two approaches and data from them for integrated and synergistic use.

From the investigations in this paper, there are a few critical issues and challenges to be noted for future development of better integration of GIS and BIM. They are:

1) To reduce the data redundancy from BIM to GIS is an important aspect in data transformation, according to different applications;

2) More effective and automated methods are necessary for data transformation from multi-source data formats including IFC, CityGML, dwg, dgn, rvt, nwf/nwd, obj, 3ds, etc.;

3) The complexity of the topological relationships in $3 \mathrm{D}$ spatial environments requires new approaches or rules for 3D topological reconstruction from BIM;

4) Effective methods are necessary for the reuse of geometry and semantic information from BIM in GIS.

\section{REFERENCES}

Cheng, J., Deng, Y., Du, Q., 2013. Mapping between BIM models and 3D GIS city models of different levels of detail. Proceedings of the 13th international conference on construction applications of virtual reality, London.

de Laat, R., van Berlo, L., 2011. Integration of BIM and GIS: The development of the CityGML GeoBIM extension Advances in 3D geo-information sciences, Springer, pp. 211-225.

Donkers, S., 2013. Automatic generation of CityGML LoD3 building models from IFC models. TU Delft University of Technology.

Eastman, C., Teicholz, P., Sacks, R., Liston, K., 2011. BIM handbook: A guide to building information modeling for owners, managers, designers, engineers and contractors: John Wiley \& Sons.

ISO, 2013. Industry Foundation Classes (IFC) for data sharing in the construction and facility management industries. Available at: http://www.iso.org/iso/catalogue_detail.htm?csnumber=51622.

Tang, S., Zhu, Q., Zhao, J., 2014. Towards Interoperating of BIM and GIS Model: Geometric and Semantic Integration of CityGML and IFC Building Models. Journal of Information Technology in Civil Engineering and Architecture, No. 8, pp. 11-17. 